\title{
Asymptomatic giardiasis and growth in young children; a longitudinal study in Salvador, Brazil
}

\author{
M. S. PRADO ${ }^{1}$, S. CAIRNCROSS ${ }^{*}$, A. STRINA ${ }^{1}$, M. L. BARRETO ${ }^{1}$, \\ A. M. OLIVEIRA-ASSIS ${ }^{3}$ and S. REGO ${ }^{1}$ \\ ${ }^{1}$ Institute of Public Health, Universidade Federal da Bahia, Rua Padre Feijó 29, $4^{\circ}$ andar, 40110-170 Salvador - BA, Brazil \\ ${ }^{2}$ London School of Hygiene and Tropical Medicine, Keppel Street, London WC1E 7HT, UK \\ ${ }^{3}$ School of Nutrition, Universidade Federal da Bahia, Rua Araújo Pinho 32, 40110-150 Salvador-BA, Brazil
}

(Received 8 Fuly 2004; revised 5 December 2004; accepted 17 December 2004)

\section{SUMMARY}

This study sought to assess the effect of giardiasis on growth of young children. In Salvador, northeast Brazil, 597 children initially aged 6 to 45 months were followed for a year in 1998/9, measured anthropometrically thrice, every 6 months, and monitored for diarrhoea prevalence twice weekly. Stool samples were collected and examined during the second round of anthropometry, and infected children were treated 39 days later, on average (s.D. 20 days). For each 6-month interval, the gains in z-scores of infected and uninfected children were compared, after adjustment for potential confounding factors, including longitudinal prevalence of diarrhoea. No significant difference was found for the first interval but in the second, the gain in adjusted height-for-age z-score was 0.09 less in infected than uninfected children, equivalent to a difference in height gain of $0.5 \mathrm{~cm}$. The shortfall in growth was greater in children who remained free of diarrhoea, and was significantly correlated with the proportion of the second interval during which the child had remained untreated. We conclude that Giardia can impede child growth even when asymptomatic, presumably through malabsorption. This finding challenges the view that young children found to have asymptomatic giardiasis in developing countries should not be treated.

Key words: Brazil, diarrhoea, Giardia duodenalis, growth, longitudinal study, malabsorption, nutritional status.

\section{INTRODUCTION}

Giardia duodenalis is a common intestinal pathogen, particularly among pre-school children in both industrialized and developing countries. The prevalence of infection varies typically from $2 \%$ to $5 \%$ in the industrialized countries and from $20 \%$ to $30 \%$ in the developing world (Shetty et al. 1990; Sullivan et al. 1991), with an estimated global total of some 200 million people infected (WHO, 1981).

Infection with Giardia duodenalis generally occurs without clinical symptoms, though it can affect nutritional status due to diarrhoea (Islam, 1990), loss of appetite (Crompton, 1984; Rosenberg \& Bowman, 1984), and reduced absorption of proteins, vitamins A, $B_{12}$ and lactose (Walterspiel \& Pickering, 1994). However, there are few conclusive studies to demonstrate the effects in the community, other than from diarrhoea. Guatemalan children infected with $G$. duodenalis have been shown to gain weight after treatment with metronidazole (Gupta \& Urrutia, 1982). On the other hand, a cross-sectional study of children under 5 years of age in São Paulo, Brazil (Muniz et al. 2002) found no significant association

* Corresponding author: London School of Hygiene and Tropical Medicine, Keppel Street, London WC1E 7HT, UK. Tel: +44207927 2211. Fax: +442076367643. E-mail: sandy.cairncross@1shtm.ac.uk between giardiasis and growth. Checkley et al. (1997) found that asymptomatic cryptosporidiosis affected the growth of Peruvian children under the age of 2 , and stressed the need to determine whether asymptomatic infections with agents other than Cryptosporidium also cause growth faltering. The present study assesses the association between giardiasis and the growth of children under 4 years old in the city of Salvador, Northeast Brazil.

\section{MATERIALS AND METHODS}

This longitudinal study was carried out in the city of Salvador, with a population of approximately $2 \cdot 3$ million, or 6630 inhabitants $/ \mathrm{km}^{2}$ (FIBGE, 1991). The sample of 792 children under the age of 3 was chosen from the study population of a larger citywide study of the health impact of sanitation measures (Teixeira et al. 2002). Households were chosen at random from a census of the 30 sampling areas in the main study. When a household had more than 1 child under the age of 3 , one child was chosen at random.

Informed consent to participate was obtained from the parents or guardians of all the children studied, and the protocol for the study was approved by the Ethics Committee of the Federal University of Bahia. 


\section{Anthropometry}

Anthropometric measurements of nutritional status were carried out from December 1997 to March 1999, measuring each child 3 times, every 6 months. Their growth was thus measured over two 6-month time-intervals. At the time of the first measurement, the children were aged 6 to 45 months. Though it took 3 months to complete each round of anthropometric measurements, care was taken to ensure that the interval for each child was kept to 6 months, within a week or two. For example, the mean period between the second and third rounds was 6 months and 6 days (S.D. 16 days).

Each child was measured twice by different teams of trained and supervised field workers, using portable digital weighing scales and measuring equipment. The children were weighed without clothes using a digital scale (Filizola, São Paulo, model E-150/3P), and if the results of the two teams differed by more than $100 \mathrm{~g}$ they were re-weighed. Height was measured with the child lying dorsally on a flat surface, using the recommended methods (Lohman, Roche \& Martorell, 1988), and the measurements repeated if they differed by more than $0.5 \mathrm{~cm}$. Heights of children aged 24 months or older were adjusted for the effect of prone measurement by subtracting $1 \mathrm{~cm}$ as recommended by WHO (1995). z-scores for weight-for-age, weight-for-height and height-for-age were calculated using the EPINUT program (Epi Info 6.0; CDC, Atlanta, GA, USA).

\section{Collection and examination of stool samples}

Stool samples were collected and examined for $G$. duodenalis infection in the space of 4 months from the end of May to the beginning of September 1998, coinciding roughly with the second round of anthropometric measurements.

The mother or carer of each child was visited at home and given a numbered, labelled container for stool collection. These were collected the following morning and taken immediately on ice for analysis the same day in the Parasitology Laboratory of the Instituto de Saúde Coletiva. A single stool sample was examined using the Kato-Katz method for the presence and number of helminth eggs, and simple sedimentation for Giardia cysts (Neva \& Brown, 1994). When cysts of $G$. duodenalis were found in the sediment, the child was considered to be infected. All children with positive stools were treated with $60 \mathrm{mg} / \mathrm{kg}$ of metronidazole (Flagyl) daily, for 5 days. This treatment was administered an average of 1 month and 9 days (s.D. 20 days) after the second round of anthropometry; the variation in this interval was not deliberate, but due to administrative and logistical factors. Children found to be infected with intestinal helminths were treated with mebendazole at the same time.

\section{Diarrhoea symptoms}

Diarrhoea data were collected twice weekly during home follow-up visits or, for a few better-off households, by telephone. During the visit, the field worker questioned the mother or carer about the occurrence of diarrhoea in the preceding 3-4 days, asking directly " did the child have diarrhoea?" for each day, and recording the number and consistency of motions. A day with diarrhoea was defined by the occurrence of 3 or more loose or liquid motions. However, the field workers were blind to this definition.

\section{Socio-economic and other data}

Demographic, socio-economic and environmental data were obtained from a semi-structured questionnaire administered to the mother or carer of the child by trained field workers. In addition, the household was visited twice weekly to monitor for diarrhoea symptoms. Further details of the procedure are given elsewhere (Strina et al. 2003).

\section{Statistical analysis}

The data were double-entered as a quality check, using EpiInfo. Analysis and significance tests were carried out using SAS version 8.0 (SAS Institute, Cary NC, USA). For each child, the difference in weight, height and other anthropometric indicators was calculated between the first and second, and also between the second and third rounds of measurement. The mean gains in weight, height and $z$-scores of children infected and uninfected with $G$. duodenalis were compared using analysis of variance (ANOVA). These differences were controlled for potential confounding variables using ANACOVA (analysis of covariance).

\section{RESULTS}

Of the original sample of 792 children, 626 submitted samples for coprological examination and 597 of these $(75 \%)$ were measured on all 3 occasions. The overall prevalence of infection with $G$.duodenalis was $14 \cdot 5 \%$, with a higher prevalence (18.0\%) among children aged 24 months and over. Infection with Ascaris lumbricoides and Trichuris trichiura was also common, with prevalences $23 \cdot 1 \%$ and $17 \cdot 2 \%$ respectively. Entamoeba histolytica was found in the stools of only 9 children $(1 \cdot 6 \%)$.

Table 1 shows the mean age, weight, height and $z$-scores of the children in the first round of measurement and the mean 'longitudinal prevalence' (Morris et al. 1996) or proportion of days with diarrhoea, according to whether or not the child was infected with $G$. duodenalis. Infected children weighed $0.40 \mathrm{~kg}$ less and were $0.76 \mathrm{~cm}$ shorter than 
Table 1. Characteristics of children aged 6-45 months according to Giardia infection status, Salvador, 1997/8

\begin{tabular}{|c|c|c|c|c|}
\hline \multirow[b]{3}{*}{ Variable } & \multirow{2}{*}{\multicolumn{2}{|c|}{$\frac{\text { Infected }}{(n=85)}$}} & \multirow{2}{*}{\multicolumn{2}{|c|}{$\begin{array}{l}\text { Not infected } \\
(n=512)\end{array}$}} \\
\hline & & & & \\
\hline & Mean & S.E. & Mean & S.E. \\
\hline Age (months) & $21 \cdot 14$ & 0.991 & $20 \cdot 53$ & $0 \cdot 426$ \\
\hline Weight $(\mathrm{kg})$ & $10 \cdot 75$ & $0 \cdot 246$ & $11 \cdot 15$ & $0 \cdot 106$ \\
\hline Height $(\mathrm{cm})$ & $80 \cdot 88$ & $0 \cdot 875$ & $81 \cdot 64$ & $0 \cdot 403$ \\
\hline Weight for age $z$-score & $-0 \cdot 68$ & $0 \cdot 128$ & $-0 \cdot 22$ & $0 \cdot 052$ \\
\hline Height for age $z$-score & $-0 \cdot 63$ & $0 \cdot 118$ & $-0 \cdot 19$ & $0 \cdot 046$ \\
\hline Weight for height $z$-score & $-0 \cdot 29$ & $0 \cdot 115$ & $-0 \cdot 03$ & $0 \cdot 046$ \\
\hline Longitudinal prevalence of diarrhoea* & $3 \cdot 20 \%$ & $0 \cdot 74 \%$ & $2 \cdot 50 \%$ & $0 \cdot 22 \%$ \\
\hline Prevalence of Ascaris lumbricoides & $29 \cdot 4$ & & $22 \cdot 1$ & \\
\hline Prevalence of Trichuris trichiura & $25 \cdot 9$ & & $15 \cdot 6$ & \\
\hline
\end{tabular}

* During interval between first and second rounds of measurement.

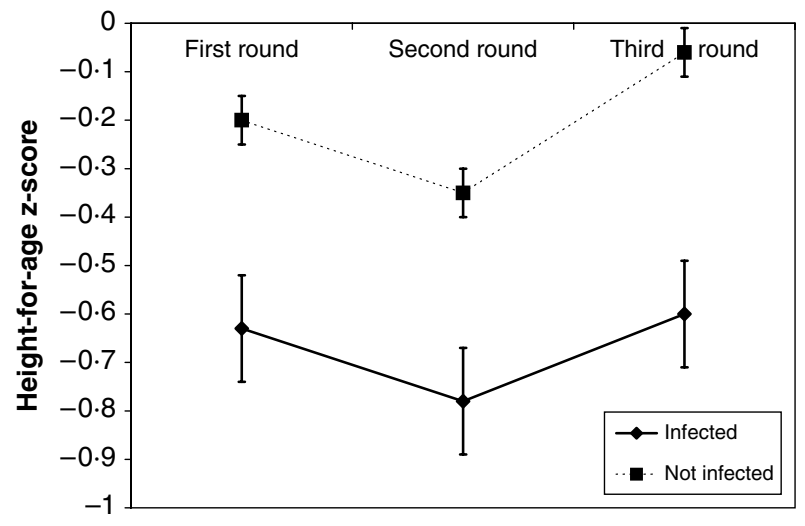

Fig. 1. Mean height-for-age $\mathrm{z}$-scores and $95 \%$ confidence intervals for children initially aged $6-45$ months, in the three rounds of measurement, Salvador, 1997/99. Scores for children found to be infected with Giardia duodenalis at the second round are shown separately.

those which were not infected. The weight-for-age and height-for-age $z$-scores of the infected children are significantly lower than those of the children without giardiasis. A similar difference is seen in the weight-for-height $\mathrm{z}$-scores, but it is not statistically significant.

The mean height-for-age $z$-scores of infected and uninfected children in the 3 successive rounds of measurement are shown in Fig. 1. The relationship between growth and infection with Giardia is potentially subject to confounding by a number of variables, particularly other infections, socioeconomic status and environmental factors which are associated with socio-economic status and with giardiasis. Each socio-economic and environmental factor previously found to be associated with giardiasis in this population (Prado et al. 2003) was considered a potential confounder if it was significantly associated with growth in weight or height.
Table 2 shows the average change in weight, height and $z$-scores during the first 6 -month interval; that is, in the period immediately before the collection of stools for examination. The means are also shown adjusted for age and sex of the child and all the potential confounders identified as described above, as well as the intensity of infection with A. lumbricoides and $T$. trichiura and the longitudinal prevalence of diarrhoea during the interval between measurements. After adjustment, the weight gain of the infected children is slightly better than for their peers, though their performance in terms of height for age is slightly worse. However, neither difference is statistically significant.

Table 3 shows the corresponding gains registered during the second interval, adjusted as before. The adjusted mean gain in height and in height-for-age $z$-score is significantly lower in infected children than in those who were free from giardiasis. The gain in weight and in weight-for-age $z$-score is also lower, but not significantly so. We repeated this analysis separately for children aged 6 to 23 months and those aged 24 to 45 months (data not shown). The association between giardiasis and reduced weight gain was still significant in both age groups after adjustment.

These data suggest that giardiasis affects linear growth irrespective of the diarrhoea associated with it. The growth of children with and without Giardia infection was therefore compared in the limited number of children who remained free of diarrhoea throughout the second measurement interval (Table 4). The mean gains in height and in height-for-age were significantly lower in the infected children.

The hypothesis that infection with Giardia is associated with impeded growth was also tested in a different way, using the variability of the time between stool examination and treatment, and consequent variation in the proportion of the interval 
Table 2. Mean gain in weight and height in children initially aged 6-45 months, from first to second round of measurement, Salvador, 1998

\begin{tabular}{|c|c|c|c|c|c|c|c|}
\hline \multirow[b]{3}{*}{ Variable } & \multicolumn{6}{|c|}{ Infection with Giardia duodenalis } & \multirow[b]{3}{*}{$P$-value $* *$} \\
\hline & \multicolumn{3}{|c|}{$\begin{array}{l}\text { Yes } \\
(n=85)\end{array}$} & \multicolumn{3}{|c|}{$\begin{array}{l}\text { No } \\
(n=512)\end{array}$} & \\
\hline & Mean & $\begin{array}{l}\text { Adjusted } \\
\text { mean* }\end{array}$ & S.E. & Mean & $\begin{array}{l}\text { Adjusted } \\
\text { mean* }\end{array}$ & S.E. & \\
\hline Weight (kg) & $1 \cdot 24$ & $1 \cdot 28$ & $0 \cdot 06$ & $1 \cdot 29$ & $1 \cdot 28$ & $0 \cdot 02$ & $0 \cdot 48$ \\
\hline Height $(\mathrm{cm})$ & $4 \cdot 54$ & $4 \cdot 59$ & $0 \cdot 18$ & $4 \cdot 85$ & $4 \cdot 83$ & $0 \cdot 07$ & $0 \cdot 11$ \\
\hline Weight for age $z$-score & $0 \cdot 04$ & $0 \cdot 01$ & $0 \cdot 05$ & $-0 \cdot 02$ & $-0 \cdot 01$ & $0 \cdot 02$ & $0 \cdot 36$ \\
\hline Height for age $z$-score & $-0 \cdot 15$ & $-0 \cdot 18$ & $0 \cdot 05$ & $-0 \cdot 15$ & $-0 \cdot 15$ & $0 \cdot 02$ & $0 \cdot 27$ \\
\hline Weight for height $z$-score & $0 \cdot 14$ & $0 \cdot 11$ & $0 \cdot 06$ & $0 \cdot 09$ & $0 \cdot 10$ & $0 \cdot 02$ & $0 \cdot 42$ \\
\hline
\end{tabular}

* Mean adjusted for sex, age of child (months), house floods during rain, presence of rubbish near house, duration of interval between measurements, prevalence of diarrhoea during that interval and intensity of infection (eggs/g of stool) with Ascaris lumbricoides and Trichuris trichiura. z-scores are also adjusted for their initial values.

** P-value for difference between adjusted means.

Table 3. Mean gain in weight and height in children initially aged $6-45$ months, from second to third round of measurement, Salvador, 1998/9

\begin{tabular}{|c|c|c|c|c|c|c|c|}
\hline \multirow[b]{3}{*}{ Variable } & \multicolumn{6}{|c|}{ Infection with Giardia duodenalis } & \multirow[b]{3}{*}{$P$-value** } \\
\hline & \multicolumn{3}{|l|}{$\begin{array}{l}\text { Yes } \\
(n=85)\end{array}$} & \multicolumn{3}{|c|}{$\begin{array}{l}\text { No } \\
(n=512)\end{array}$} & \\
\hline & Mean & $\begin{array}{l}\text { Adjusted } \\
\text { mean* }\end{array}$ & S.E. & Mean & $\begin{array}{l}\text { Adjusted } \\
\text { mean* }\end{array}$ & S.E. & \\
\hline Weight (kg) & $1 \cdot 01$ & $1 \cdot 04$ & $0 \cdot 06$ & $1 \cdot 11$ & $1 \cdot 11$ & $0 \cdot 02$ & $0 \cdot 15$ \\
\hline Height $(\mathrm{cm})$ & $4 \cdot 89$ & $4 \cdot 96$ & $0 \cdot 19$ & $5 \cdot 48$ & $5 \cdot 46$ & $0 \cdot 08$ & $0 \cdot 01$ \\
\hline Weight for age $z$-score & $0 \cdot 00$ & $-0 \cdot 02$ & $0 \cdot 04$ & $0 \cdot 02$ & $0 \cdot 02$ & $0 \cdot 02$ & $0 \cdot 18$ \\
\hline Height for age $z$-score & $0 \cdot 18$ & $0 \cdot 19$ & $0 \cdot 05$ & $0 \cdot 29$ & $0 \cdot 28$ & $0 \cdot 02$ & $0 \cdot 05$ \\
\hline Weight for height z-score & $-0 \cdot 12$ & $-0 \cdot 15$ & $0 \cdot 05$ & $-0 \cdot 17$ & $-0 \cdot 17$ & $0 \cdot 02$ & $0 \cdot 38$ \\
\hline
\end{tabular}

* Means adjusted as in Table 2 .

** $P$-value for difference between adjusted means.

Table 4. Mean gain in weight and height from second to third round of measurement in children free of diarrhoea, Salvador, 1998/9

\begin{tabular}{|c|c|c|c|c|c|c|c|}
\hline \multirow[b]{3}{*}{ Variable } & \multicolumn{6}{|c|}{ Infection with Giardia duodenalis } & \multirow[b]{3}{*}{$P$-value $* *$} \\
\hline & \multicolumn{3}{|c|}{$\begin{array}{l}\text { Yes } \\
(n=85)\end{array}$} & \multicolumn{3}{|c|}{$\begin{array}{l}\text { No } \\
(n=512)\end{array}$} & \\
\hline & Mean & $\begin{array}{l}\text { Adjusted } \\
\text { mean* }\end{array}$ & S.E. & Mean & $\begin{array}{l}\text { Adjusted } \\
\text { mean* }\end{array}$ & S.E. & \\
\hline Weight (kg) & $0 \cdot 97$ & $0 \cdot 97$ & $0 \cdot 08$ & $1 \cdot 10$ & $1 \cdot 10$ & $0 \cdot 03$ & $0 \cdot 09$ \\
\hline Height $(\mathrm{cm})$ & $4 \cdot 69$ & $4 \cdot 69$ & $0 \cdot 29$ & $5 \cdot 37$ & $5 \cdot 37$ & $0 \cdot 12$ & $0 \cdot 03$ \\
\hline Weight for age $z$-score & $-0 \cdot 02$ & $-0 \cdot 02$ & $0 \cdot 05$ & $0 \cdot 00$ & $0 \cdot 01$ & $0 \cdot 02$ & $0 \cdot 36$ \\
\hline Height for age $z$-score & $0 \cdot 13$ & $0 \cdot 13$ & $0 \cdot 07$ & $0 \cdot 29$ & $0 \cdot 29$ & $0 \cdot 03$ & $0 \cdot 03$ \\
\hline Weight for height z-score & $-0 \cdot 11$ & $-0 \cdot 11$ & $0 \cdot 07$ & $-0 \cdot 19$ & $-0 \cdot 19$ & $0 \cdot 03$ & $0 \cdot 17$ \\
\hline
\end{tabular}

* Means adjusted as in Table 2 .

** $P$-value for difference between adjusted means.

between measurements for which each child remained infected. Restricting the analysis to the infected children, a linear regression showed that the gain in height-for-age $z$-score was significantly associated with the proportion of the interval between the second and third rounds of anthropometry for which each child remained untreated (Beta= $-0.239, P=0.022)$. Adjustment for the prevalence 
of diarrhoea did not alter the significance of this association.

\section{DISCUSSION}

The relative timing of stool examination, treatment and the intervals of growth monitoring in our study is important, but not because of seasonality; another longitudinal study in the region has shown that, contrary to the pattern for Cryptosporidium, infection with Giardia shows no seasonal pattern or association with rainfall (Newman et al. 2001). It is important because other studies, involving a single measurement of nutritional status, have been unable to distinguish whether any association between giardiasis and malnutrition arises from an effect of giardiasis on growth or from increased susceptibility of malnourished children to infection (Newman et al. 2001).

The lack of an association between infection and growth in the first interval shows that the association found in the second interval is not a consequence of reverse causality - that is, it does not occur because children whose growth is faltering are more susceptible to infection. Indeed, it would be difficult to exclude that possibility more conclusively, except by means of study designs which would be difficult to justify ethically.

Nor is the effect of Giardia infection on children's growth a result of greater frequency or duration of diarrhoea symptoms, whether caused by the Giardia or by other pathogens, because the effect was still significant after controlling for longitudinal prevalence of diarrhoea, which reflects both frequency and duration, and in those children who had not suffered any diarrhoea at all during the measurement interval.

Ascariasis and trichuriasis were prevalent in our study population ( $23 \%$ and $17 \%$ respectively), and are also known to affect children's growth. However, their influence too can be ruled out in this case as we controlled for infection with those parasites. Given the especially strong impact of trichuriasis infection on linear growth, we repeated the analysis, restricting it to those children uninfected with Trichuris (data not shown). The difference in adjusted mean growth was greater in this restricted sample, whether measured in terms of height or height-for-age z-score.

We did not look for Cryptosporidium in the stool samples; it is not common in cross-sectional surveys, particularly in the season when the samples were collected. However, we do not consider that pathogen a plausible cause of the differences we have found, because of two findings from a large longitudinal study in the same region of Brazil (Newman et al. 2001). First, there was no sign of interaction between Giardia and Cryptosporidium. Second, Cryptosporidium was found only in the stools of symptomatic patients, not in non-diarrhoeal stools.
We conclude that giardiasis impedes the growth of young children during the asymptomatic periods which constitute the majority of the duration of their infection, presumably through malabsorption. Of course, it is possible that other unidentified confounding factors may be operating, but we believe we have excluded the most likely ones.

The examination of a single stool sample by simple sedimentation is not sufficient to detect all cases of infection, and no doubt some children were wrongly classified as uninfected. However, such misclassification would be likely to reduce the observed differential growth rates between the groups, rather than to increase it. The differences we have found are thus more likely to be underestimates than overestimates.

Checkley et al. (1997) did not mention an impact on nutrition from giardiasis, although they did collect data on Giardia infection and on growth. However, their sample of 185 children was one third the size of ours, and their appeal for further studies of the impact of such pathogens on growth suggests that, if they could not demonstrate a significant impact from Giardia, they still considered it likely.

Our findings contrast with those of Muniz et al. (2002) who found no association between Giardia infection and growth. However, their study was cross-sectional in design and so unable to compare rates of growth over a limited period of time when infection status was ascertained. Indeed, such a study can only detect impeded growth occurring before the ascertainment of infection, and we too did not find this. Moreover, because of the lower prevalence in their study area, the number of infected children in their study was less than in ours. Their average age was also older, whereas Checkley et al. (1997) found that the effect of Cryptosporidium on growth was greatest in the youngest children.

We have found a greater impact on longitudinal growth than on weight gain, and this dimension is harder to recover through subsequent 'catch-up' growth. Indeed, a follow-up study of the effect of Cryptosporidium on growth (Checkley et al. 1998) found that there was a lasting adverse effect on the linear growth of children who were infected at an early age. It is likely that the effect we have found due to Giardia is also a lasting one.

Our findings have important implications for the management of asymptomatic giardiasis in developing countries. It is widely accepted that children in developing countries who are found to be infected with Giardia but are not suffering from diarrhoea symptoms should not normally be offered treatment (Gilman et al. 1988), as they will soon become reinfected and it will do them little harm. We believe that, in the light of our findings, this assumption needs to be re-examined. 
Financial support for this study was provided by the $\mathrm{CNPq} /$ Pronex Programme of the Brazilian federal government (contract no. 661086/1998-4) and the Secretaria de Infraestrutura of the state government of Bahia. The authors thank the fieldwork team, especially their supervisor, J. C. Goes, and also Dr Graham Clark and Dr Ann Ashworth Hill for their comments on a draft of this paper.

\section{REFERENCES}

CHECKLEY, W., EPSTEIN, L. D., GILMAN, R. H., BLACK, R. E., CABrera, L. \& STERling, C. R. (1998). Effects of Cryptosporidium parvum infection in Peruvian children; growth faltering and subsequent catch-up growth. American Fournal of Epidemiology 148, 497-506.

ChECKley, W., GILMAN, R. H., EPSTEIn, L. D., SUAREZ, M., DIAZ, J. F., CABRERA, L., BLACK, R. E. \& STERLING, C. R. (1997). Asymptomatic and symptomatic cryptosporidiosis : their acute effect on weight gain in Peruvian children. American Fournal of Epidemiology 145, 156-163.

CROMPTON, D. W. T. (1984). Influence of parasitic infection on food intake. Federation Proceedings 43, 239-245.

FIBGE (1991). Censo demográfico - Bahia. Fundação Instituto Brasileiro de Geografia e Estatística, Rio de Janeiro.

Gilman, R. H., MARQUis, G. S., Miranda, E., Vestegui, M. \& MARTINEZ, H. (1988). Rapid reinfection by Giardia lamblia after treatment in a hyperendemic Third World community. Lancet 8581, 343-345.

GUPTA, M. C. \& URRUTIA, J. J. (1982). Effect of periodic antiascaris and antigiardia treatment on nutritional status of preschool children. American Fournal of Clinical Nutrition 36, 79-86.

ISLAM, A. (1990). Giardiasis in developing countries. In Giardiasis (ed. Meyer, E. A.), pp. 235-265. Elsevier, Amsterdam.

LOHMAN, T. G., ROCHE, A. F. \& MARTORELL, R. (1988). Anthropometric Standardization Reference Manual. Ilinois, Human Kinetics Books.

MORRIS, S. S., COUSENS, S. N., KIRKWOOD, B. R., ARTHUR, P. \& ROSS, D. A. (1996). Is prevalence of diarrhea a better predictor of subsequent mortality and weight gain than diarrhea incidence? American Fournal of Epidemiology 144, 582-588.

MUNiz, P. T., FERreira, M. U., FERrEira, C. S., CONDE, W. L. \& MONTEIRO, C. A. (2002). Intestinal parasitic infections in young children in São Paulo, Brazil: prevalences, temporal trends and associations with physical growth. Annals of Tropical Medicine and Parasitology 95, 503-512.

NEVA, F. A. \& BROWn, H. W. (1994). Basic Clinical Parasitology, 6th Edn. Appleton and Lange. Norwalk, USA.

NEWMAN, R. D., MOORE, S. R., LIMA, A. A. M., NATARo, J. P., GUERRANT, R. L. \& SEARS, C. L. (2001). A longitudinal study of Giardia lamblia infection in north-east Brazilian children. Tropical Medicine and International Health $\mathbf{6}$, 624-634.

PRADO, M. S., BARRETO, M. L., OLIVEIRA-ASSIS, A. M., PAZ, L. M. \& CAIRNCRoss, s. (2003). Risk factors for infection with Giardia duodenalis in pre-school children in the city of Salvador, Brazil. Epidemiology and Infection 131, 899-906.

ROSENBERG, I. H. \& BOWMAN, A. B. B. (1984). Impact of intestinal parasites on digestive function in humans. Federation Proceedings 43, 246-250.

SHETTY, N., NARASIMHa, M., RAGHUVEer, T. S., ELliotT, E., FARTHING, M. J. \& MACADEN, R. (1990). Intestinal amoebiasis and giardiasis in Southern Indian infants and children. Transactions of the Royal Society of Tropical Medicine and Hygiene 84, 382-384.

STRINA, A., CAIRNCROSS, S., BARRETO, M. L., LARREA, C. \& PRADO, M. S. (2003). Childhood diarrhea and observed hygiene behavior in Salvador, Brazil. American fournal of Epidemiology 157, 1032-1038.

SUlLIVAN, P. B., MARSH, M. N., PHILliPS, M. B., DEWIT, O., NEALE, G., CEVAllos, A. M., YAMSON, P. \& FARTHing, M. J. (1991). Prevalence and treatment of giardiasis in chronic diarrhoea and malnutrition. Archives of Disease in Childhood 66, 304-306.

TEIXEIRA, M. G. L. C., BARRETO, M. L., COSTA, M. C. N., STRINA, A., MARTINS, D. F. J. \& PRADO, M. S. (2002). Sentinel areas: a monitoring strategy in public health. Cadernos de Saúde Pública 18, 1189-1195.

walterspiel, J. N. \& PICKERING, L. K. (1994). Giardia and giardiasis. Progress in Clinical Parasitology 4, 1-26.

WORLD HEALTH ORGANIZATION (1981). Intestinal protozoal and helminth infections. Technical Report Series No. 666. World Health Organization, Geneva, pp. $49-55$.

WORLD HEALTh ORGanization (1995). Physical status; the use and interpretation of anthropometry. Technical Report Series No. 854. World Health Organization, Geneva. 